Journal of Management and Bussines (JOMB)

Volume 1, Nomor 2, Desember 2019

p-ISSN : 2656-8918

e-ISSN:2684-8317

DOI : https://doi.org/10.31539/jomb.v1i2.687

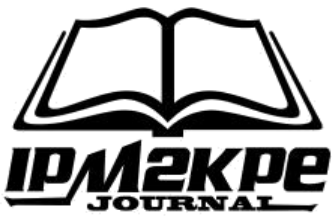

\title{
PENERAPANPREVENTIVE MAINTENANCE UNTUK MENGURANGI FAILURE PRODUCT DI PANGAN SEJAHTERA PABRIK TAUCO KOTA SUKABUMI
}

\author{
Zahra Syahmia Haidar $^{1}$, Erry Sunarya ${ }^{2}$, Kokom Komariah ${ }^{3}$ \\ Universitas Muhammadiyah Sukabumi ${ }^{1,2,3}$ \\ zsyahmia33@gmail.com ${ }^{1}$
}

\begin{abstract}
ABSTRAK
Tujuan penelitian ini adalah untuk menerapkan adanya kegiatan preventive maintenance supaya berjalan diperusahaan, untuk mengurangi angka failure productyang sering terjadi di perusahaan pangan sejahtera pabrik tauco kota Sukabumi. Penelitian ini menggunakan metode deskriptif kualitatif dengan menggunakan metode fishbone atau sering disebut juga dengan diagram sebab akibat dengan melakukan wawancara tidak terstruktur pada karyawan yang bekerja di perusahaan terutama pada bagian produksi. Hasil analisis yang dilakukan penulis dengan menggunakan metode Fishbone untuk menjabarkan apasaja ketidak normalan yang terjadi pada perusahaan khususnya pada bagian mesin untuk produksi dengan memasukkan dimensi-dimensi Preventive maintenance kedalam kolom fishbone dan ditemukanlah beberapa kesalahan yang dilakukkan dalam dimensi tersebut di lapangan. Simpulan, Penerapan Preventive Maintenance pada UMKM Pangan Sejahtera Pabrik Tauco Kota Sukabumi benar-benar bekerja sesuai tujuan yang penulis mau yaitu menekan angka Failure Product yang cukup tinggi
\end{abstract}

Kata Kunci: Preventive Maintenance, Failure Product

\begin{abstract}
The purpose of this study is to implement preventive maintenance activities to run in the company, to reduce the number of product failures that often occur in the prosperous food company in the Tauco city of Sukabumi. This study uses a qualitative descriptive method using the fishbone method or often referred to as a causal diagram by conducting unstructured interviews with employees who work in companies, especially in the production department. The results of the analysis conducted by the author using the Fishbone method to describe any abnormalities that occur in the company, especially in the engine for production by entering the dimensions of Preventive maintenance into the fishbone column and found several errors that were made in these dimensions in the field. Conclusion, The Implementation of Preventive Maintenance in Prosperous Food MSME of the Tauco Factory in Sukabumi City really works in accordance with the objectives that the author wants to reduce the Failure Product numbers which are quite high
\end{abstract}

Keywords: Preventive Maintenance, Failure Product 


\section{PENDAHULUAN}

Dalam suatu perusahaan, terutama perusahaan yang memproduksi sebuah produk dengan skala besar tentu sangat dibutuhkan peralatan dan mesin yang dapat mempermudah dan menjaga mutu serta kualitas dari produk yang diproduksi tersebut agar dapat diterima atau dikonsumsi oleh pasar.

Perusahaan yang berskala menengah ke atas terutama perusahaan yang menjual barang, pasti memiliki peralatan atau mesin yang digunakan untuk memproses produk mereka menjadi barang yang siap jual, karena perusahaan berskala menengah ke atas memproduksi barang dalam jumlah yang banyak. Mesin yang digunakan perusahaan tidak hanya untuk mempermudah pengerjaan produk saja, namun mesin yang dipakai berfungsi juga sebagai quality control dari produk yang akan dipasarkan tersebut, karena mesin yang digunakan untuk mempermudah proses produksi barang itu mempunyai pengaturan dan spesifikasi yang telah diatur.

Tujuan dipergunakannya mesin dalam proses produksi yaitu untuk menghindari adanya kesalahan dan kegagalan pada produk. Produsen pastilah memiliki suatu spesifikasi tertentu untuk produknya supaya mutu dan kualitas produk terjaga ketika dipasarkan dan diterima oleh konsumen. Ukuran dari spesifikasi tersebut kemudian di input dalam pengaturan mesin, agar produk sesuai dengan standar perusahaan dan mengecilkan kemungkinan kegagalan pada produk. Kegagalan dalam produk itu termasuk kesalahan yang terjadi pada bahan baku yang salah takaran, sehingga mempengaruhi produk. Bisa juga kegagalan terjadi karena packaging yang tidak sesuai standar dan cacat. Jika sudah terjadi kesalahan demikian, perusahaan tidak mungkin akan memasarkan produk tersebut karena produk sudah dikatakan failure product. Jika produsen tetap memaksakan ingin menjual failure product tersebut karena berfikir jika tidak dijual maka akan merugikan perusahaan, justru yang akan terjadi adalah citra perusahaan dipasar akan tercoreng dan tercemar karena memasarkan failure product. Dan akan menurunkan rasa kepercayaan pelanggan kepada perusahaan. Dan itu adalah kerugian besar untuk perusahaan (Pandi, 2014).

Memiliki mesin pembantu saja belum cukup untuk menghilangkan resiko kegagalan pada produk, untuk itu sangat diperlukan juga perawatan pada mesin agar mesin senantiasa beroperasi dengan sehat dan dapat menjaga mutu produk. Jika hanya membiarkan mesin bekerja terus menerus untuk menghandle produk, tanpa adanya 
perawatan, mesin akan error dan dapat menyebabkan pengaturan spesifikasi produk yang telah diatur dalam mesin akan menjadi kacau dan dapat menimbulkan pula kegagalan dalam produk, bahkan jika tidak dilakukan pemeliharaan secara tepat pada mesin, akan menyebabkan mesin rusak lebih cepat sebelum waktunya. Maka dari itu, pemeliharaan mesin sangatlah penting, apalagi pemeliharaan untuk pencegahan terjadinya kerusakan secara dini pada mesin yang biasa disebut juga preventive maintenance.

Dengan melakukan preventive maintenance terhadap mesin-mesin yang membantu proses produksi, perusahaan dapat menjaga standar mutu dan kualitas dari produk tersebut. Jika produk yang dijual adalah produk yang berkualitas, pastilah akan menjaga kepercayaan pelanggan dan perusahaan mempunyai image yang bagus. Dengan menerapkan preventive maintenance juga dapat mengecilkan kemungkinan terjadinya kegagalan produk yang diproduksi. Karena yang paling penting bagi perusahaan adalah kepuasan konsumen dan konsumen pasti akan puas dan kembali lagi membeli jika produk yang dijual perudahaan bermutu dan berkualitas tanpa ada kecacatan.

UKM Pangan Sejahtera pabrik tauco Kota Sukabumi adalah perusahaan berskala menengah yang memproduksi produk makanan tauco. UKM Pangan Sejahtera Pabrik Tauco Kota Sukabumi memiliki nomor SIUP 503/95/PK/III/BPMPT/2013. UKM Pangan Sejahtera Pabrik Tauco memproduksi tauco dengan kemasan botol dan cup. Pabrik ini mempunyai sekitar 45 orang pekerja. Mereka mempunyai mesin sealer cup namun tidak menerapkan preventive maintenance sehingga menyebabkan seringnya terjadi kegagalan dalam pengemasan alias dapat menyebabkan kegagalan produk. Perusahaan tidak menerapkan preventive maintenance karena mereka hanya melakukan perbaikan mesin ketika mesin sudah mengalami kerusakan dan otomatis itu akan menjadikan biaya perbaikan lebih mahal bahkan bisa saja mesinnya diganti, juga dapat menyebabkan kerugian waktu karena selama masa perbaikan pasti tidak akan ada proses produksi yang berjalan. Pentingnya diterapkan preventive maintenance di UKM ini yaitu untuk meminimalisir biaya perbaikan atau mengantisipasi kerusakan yang menyebabkan mesin tidak berfungsi total yang mana pada akhirnya akan menyebabkan perusahaan membeli mesin baru untuk yang paling fatalnya. Selain itu, manfaat menerapkan preventive maintenance ini untuk menekan supaya berkurangnya kegagalan 
pada produk terutama pada saat proses pengemasan. Penulis mendapatkan data setelah mewawancarai narasumber yaitu seorang pegawai di UKM Pangan Pejahtera pabrik tauco Kota Sukabumi, tentang seberapa banyaknya terjadi kegagalan dalam mesin selama tiga bulan terakhir, diantaranya pernah mencapai angka sekitar 7\% kegagalan produk.

\section{KAJIAN TEORI}

\section{Preventive Maintenance}

"Preventive maintenance, yaitu pemeliharaan pencegahan yang dilakukan dengan waktu tetap untuk menjaga mesin tetap bekerja baik". (Assauri 2008).

Dan terakhir dari pernyataan menuru Dede Sudrajat (2016) adalah sebagai berikut "Preventive maintenance bertujuan untuk mencegah kerusakan peralatan yang sifatnya mendadak. Pelaksanaan perawatan biasanya dilakukan pada interval waktu yang direncanakan."

\section{Failure Product}

"Failure product adalah produk gagal yang sulit dikembangkan karena terkena kesan negatif, entah itu dari isi, bau, warna, kemasan, bahan baku, proses produksi yang tidak sesuai dengan standar kualitas mutu produk perusahaan bisa disebut produk gagal" (Juliani, 2008).

Jika failure product lolos kepada konsumen dan kemudian menimbulkan kerugian, maka perusahaan harus mengganti kerugian yang dialami konsumen. Salah satu dampak negatif yang diakibatkan adalah runtuhnya reputasi perusahaan dimata konsumen (Puspitasari 2014).

\section{METODE PENELITIAN}

\section{Metode Fishbone}

Fishbone atau disebut juga diagram Sebab Akibat (Cause and Effect Diagram) diperkenalkan oleh Dr. Kaoru Ishikawa pada tahun 1943. Diagram ini terdiri dari sebuah panah horizontal yang panjang dengan deskripsi masalah. Penyebab-penyebab masalah digambarkan dengan garis radial dari garis panah yang menunjukan masalah. 
Fishbone digunakan untuk memecahkan masalah dengan memaparkan dimensidiemnsi preventive maintenance pada kolom kolom yang beruas-ruas tukang ikannya lalu dijabarkan lagi dengan penjelasan-penjelasan dan deskripsi-deskripis serta gambaran apa saja masalah yang terjadi pada dimensi dari bidang-bidang yang ada tersebut yang dapat kitra lihat dan ketahui di perusahaan atau lapangan yang sedang kita observasi. Namun semata-mata kita tidak hanya mencari apa saja masalah yang terjadi pada tiap-tiap bidang dimensi yang ada pada preventive maintenance yang biasanya kerap berada pada mesin-mesin yang ada diperusahaan pangan sejahtera pabrik tauco kota Sukabumi, tidak etis rasanya jika kita hanya memberikkan apa apa saja masalah yang terjadi pada perusahaan pangan sejahtera pabrik tauco kota Sukabumi lalu pergi tanpa basa basi alias hanya memberikkan masalah tanpa solusinya saja.

Penulis disini juga meneliti apa apa saja masalah yang terjadi pada tiap-tiap bidang-bidang dimensi preventive maintenance mendeskripiskannya dan menjabarkannya lalu penulispun dengan ilmu yang ada dan penulis emban dari perkuliahan dengan mempelajari manajemen,penulis membantu mencari solusi untuk menyelesaikan masalah yang terjadi pada pangan sejahtera pabrik tauco kota Sukabumi.

Dengan mencarikan solusi dari masalah pada bidang-bidang yang ada dalam dimensi preventive maintenance penulis berusaha agar solusi solusi yang penulis ajukkan itu akan diterapkan, diaplikasikan dan dilakukan serta dilaksanakan pada dalam kegiatan sehari-hari perusahaan karena hal itulah akan membantu berkembangnya perusahaan kearah yang lebih baik.

Kegunaan dari diagram fishbone adalah: Menganalisis sebab dan akibat suatu masalah., menentukan penyebab permasalahan dan menyediakan tampilan yang jelas untuk mengetahui sumber-sumber variasi. 


\section{HASIL PENELITIAN}

Setelah dimensi-dimensi Fishbone dimasukkan kedalam kolom-kolom tulang ikan, lalu buat lagi kolom dibawahnya masalahnya, seperti berikut:

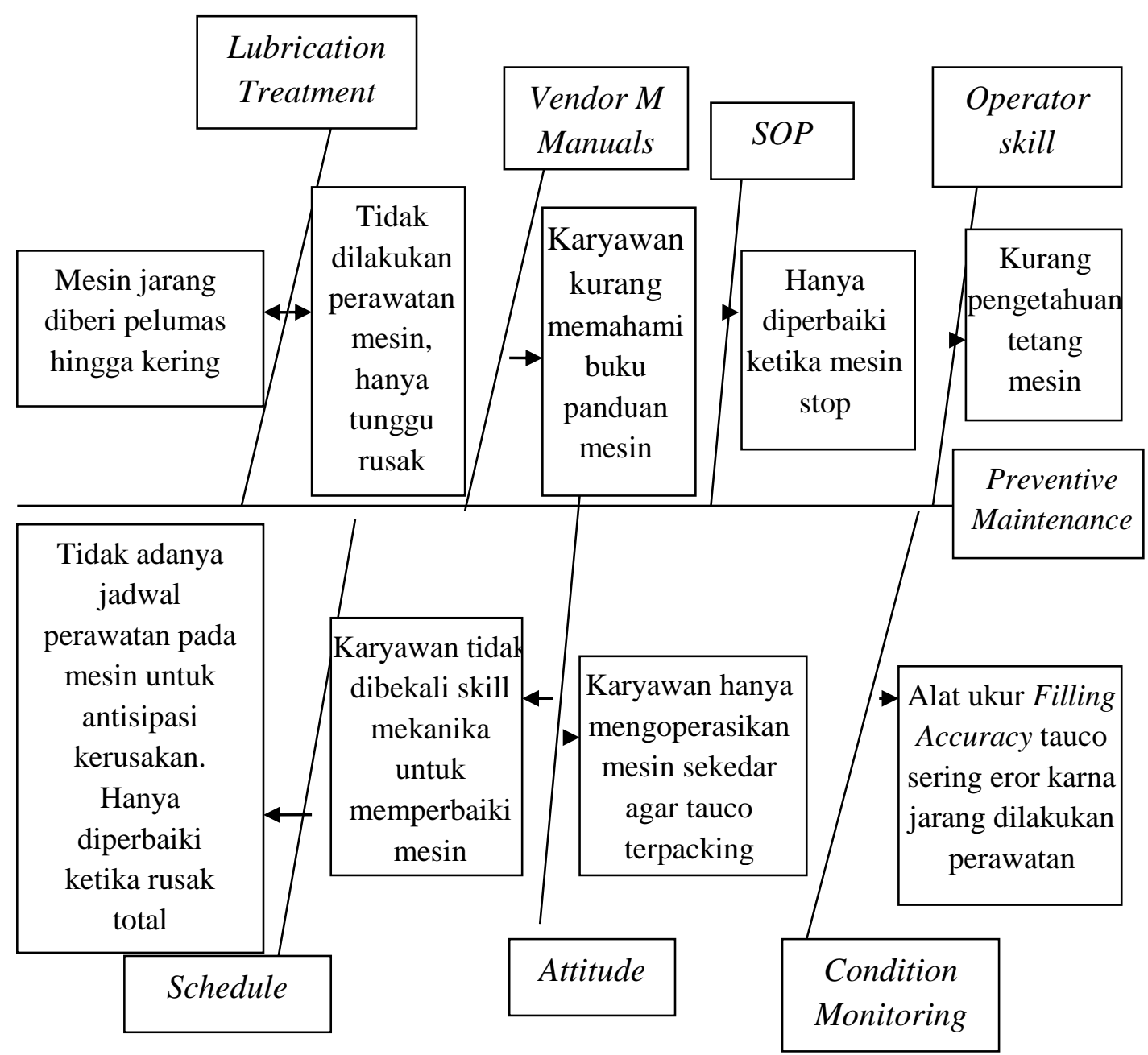

\section{Gambar 1 Diagram Fishbone}

Berdasarkan hasil analisis yang dilakukan penulis dengan menggunakan metode Fishbone untuk menjabarkan apasaja ketidak normalan yang terjadi pada perusahaan khususnya pada bagian mesin untuk produksi dengan memasukkan dimensi-dimensi Preventive maintenance kedalam kolom fishbone dan ditemukanlah beberapa kesalahan yang dilakukkan dalam dimensi tersebut di lapangan.

Setelah terbukti adanya kesalahan pada penanganan dan perawatan mesin tersebut penulis memberi solusi dari masing-masing masalah yang terjadi pada dimensi tersebut alias mulai menerapkan Preventive Maintenance pada mesin, diantaranya: 


\section{Operator Skill}

Masalah: Karyawan kurang adanya pengetahuan tentang mesin.

Solusi: Mengadakan pelatihan untuk tim produksi agar lebih memahami mesin khususnya pada karyawan operator mesin bisa dengan cara memberi buku panduan operasi mesin agar dibacadan dipahami.

\section{Standar Operation Procedur (SOP)}

Masalah: Karyawantidak mengikuti aturan untuk takaran tauco kedalam mesin filling accuracy sesuai SOP.

Solusi: Sesuaikan dengan SOP untuk takaran tauco yang akan dimasukkan kedalam tangki filling accuracy sekitar 60 liter.

\section{Vendor Maintenance Manuals}

Masalah: Masalah pada dimensi ini sama seperti masalah pada Operator Skill, yaitu karyawan yang kurang memahami mesin khususnya pada buku panduan.

Solusi: Adakan pelatihan untuk karyawan produksi dengan cara tekankan pemahaman pada buku panduan untuk mesin dan dengan arahan dari mekanika yang ahli dalam bidang mesin tersebut.

\section{Lubrication Treatment}

Masalah: Jarang dilakukan perawatan pada mesin seperti pelumasan yang jarang dan tidak terstruktur dan jarangnya diberi anti karat.

Solusi: Dibuatkan jadwal perawatan mesin yang terstruktur dan berkala atau disebut juga dengan Preventive Maintenance.

\section{Condition Monitoring}

Masalah: Alat ukur Filling Accuracy tauco sering eror karna jarang dilakukan perawatan dan sering memasukan tauco tidak sesuai takaran seperti masalah pada dimensi SOP.

Solusi: untuk takaran tauco harus sesuai dengan sop yaitu sekitar 60liter sekali isi ketika kosong jangan dipaksakan lebih dari angka itu dan jangan lupa lakukan perawatan agar mesin filling accuracybekerja dengan baik dan mengurangi error yang sering terjadi. 


\section{Memory and Tradition / Attitude}

Masalah: Karyawan hanya mengoperasikan sebatas tauco selesai dipack saja dan tidak dibekali skill mekanika untuk memperbaiki mesin, jika terjadi kerusakan mesin, maka hanya memanggil tenaga mekanik saja.

Solusi: Karyawan diberitahu dan diawasi tentang penggunaan mesin agar tidak asalasalan mengoperasikan dan juga dibekali skill memperbaiki mesin kalau-kalau terjadi keerroranmesin yang mikro.

\section{Schedule}

Masalah: Tidak adanya jadwal terstruktur perawatan pada mesin untuk antisipasi kerusakan alias tidak ada penerapan Preventive Maintenance. Hanya diperbaiki ketika rusak total dan biayanya ketika rusak bisa mencapai Rp. 250.000.000,00 hanya untuk ganti sparepartdan untuk sekali servis bisa menghabiskan Rp. 10.000.000,00

Solusi: Dibuatkan jadwal berkala dan terstruktur untuk perawatan pada mesin atau Preventive Maintenance untuk mengurangi resiko kerusakan pada sparepart dengan cara melakukan pelumasan, pemberian anti karat yang terstruktur dan terjadwal. Lalu lakukan juga perawatan servis untuk mesin satu tahun sekali untuk menjaga kesehatan mesin tetap prima.

Semua solusi dari permasalahan tersebut kemudia diterapkan dalam perusahaan termasuk menerapkan Preventive Mainteance kepada mesin, terlihat ada terjadi perubahan pada angka persentase kegagalan produk atau Failure Product yang dialami perusahaan. Yang terjadi adalah menurunnya angka Failure Product. Seperti pada table dibawah ini:

Tabel 1 Data Kegagalan Produk

\begin{tabular}{|c|c|c|c|c|c|}
\hline No & Bulan & $\begin{array}{l}\text { Tartget } \\
\text { Produk }\end{array}$ & On Product & $\begin{array}{l}\text { Failure } \\
\text { Product }\end{array}$ & $\begin{array}{l}\text { Persentase } \\
\text { Kegagalan }\end{array}$ \\
\hline 1 & November & 200.000 & 193.420 & 6.580 & $3.29 \%$ \\
\hline 2 & Oktober & 200.000 & 187.320 & 12.680 & $6.34 \%$ \\
\hline 3 & September & 200.000 & 196.000 & 4.000 & $2 \%$ \\
\hline
\end{tabular}

Sumber: wawancara dengan pimpinan pabrik tauco per 2018 
Berdasarkan tabel yang dilampirkan diatas data laporan kegagalan produk pada tiga bulan terakhir cenderung tidak stabil persentase kegagalannya. Dari persentase kegagalan pada angka sedang, besar dan jadi kecil lagi berupa 1\%. Karena biasanya kegagalan terjadi secara randomalias terjadi secara naik turun karena memang kesehatan mesin tidak terjaga dan pihak UMKM juga tidak mendata secara tertulis berapa-berapa kegagalan yang terjadi setiap produksinya.

Tabel 2 Data Kegagalan Produk

\begin{tabular}{llllll}
\hline No & Bulan & $\begin{array}{l}\text { Tartget } \\
\text { Produk }\end{array}$ & On Product & $\begin{array}{l}\text { Failure } \\
\text { Product }\end{array}$ & $\begin{array}{l}\text { Persentase } \\
\text { Kegagalan }\end{array}$ \\
\hline 1 & Februari & 200.000 & 196.600 & 3.400 & $1.7 \%$ \\
\hline 2 & Maret & 200.000 & 198.880 & 1.120 & $0.56 \%$ \\
\hline 3 & April & 200.000 & 199.350 & 650 & $0.325 \%$
\end{tabular}

Sumber: wawancara dengan karyawan bagian produksi dan telah dikonfirmasi oleh pimpinan perusahaan pabrik tauco per 2019

Dilihat dari tabel yang dipaparkan diatas dari data terakhir yang diambil pada bulan November, Oktober dan September per2018 yang mencapai kegagalan hingga 6.34\% Failure Productmengalami penurunan setelah diterapkan Preventive Maintenance dibulan Februari, Maret dan April per2019 mengalami penurunan hingga mencapai $0.325 \%$.

Hal ini menunjukkan bahwa menerapkan sistem Preventive Maintenance pada perusahaan dan menjadwalkan perawatannya akan bekerja meningkatkan keuntungan dengan menurunnya fenomena Failure Product. Maka perusahaan pun setuju untuk tetap menerapkan sistem Preventive Maintenance untuk menekan angka Failure Productnya.

\section{PEMBAHASAN}

Menurut Dede Sudrajat (2016) seperti penjelasan berikut:

Preventive maintenance adalah kegiatan dan aktivitas untuk perawatan kesehatan pada mesin dengan tujuan untuk memperlambat dan mencegah adanya terjadi suatu kerusakan agar mesin yang dimaksud tetap bekerja dan berjalan dengan lancar dan bekerja dengan semestinya tanpa terjadi suatu ke erroran pada konfigurasi dan setelan- 
setelan yang telah diatur dalam mesin untuk memproses produk,untuk menghindari kerusakan yang tak terduga pada mesin-mesin yang digunakan untuk membantu proses produksi supaya tidak terjadi suatu kesalahan dalam penhaturan mesin yang telah disetel sedemikian rupa dan dapat menuebabkan kegagalan dalam proses produksi dengan mesin error yang digunakan tersebut sehingga dapat menyebabkan kegagalan pada produk yang akan dijual di pasar atau produk dapat mengalami penurunan nilai guna dan kualitas.

Perawatan mesin pula dilakukan secara terstruktur dan terjadwal serta dilakukan secara konsisten agar mesin dapat diandalkan kerjanya dan bekerja dengan baik tanpa adanya suatu erroryang akhirnya dapat merusak mesin dan menyebabkan pengeluaran yang lebih besar untuk membeli mesin baru dibandingkan hanya memperbaiki.

Menurut Kaoru Ishikawa (1992) berikut ini:Fishbone digunakan untuk memecahkan masalah dengan memaparkan dimensi-diemnsi preventive maintenance pada kolom kolom yang beruas-ruas tukang ikannya lalu dijabarkan lagi dengan penjelasan-penjelasan dan deskripsi-deskripis serta gambaran apa saja masalah yang terjadi pada dimensi dari bidang-bidang yang ada tersebut yang dapat kitra lihat dan ketahui di perusahaan atau lapangan yang sedang kita observasi.

Berdasarkan data yang telah dipaparkan oleh Pangan Sejahtera Pabrik Tauco Kota Sukabumi yang didapatkan melalui wawancara secara terstruktur dengan pimpinan perusahaan data yang didapat pada sekitar bulan november, oktober dan September per tahun 2018 ini menampilkan kegagalan produk yang terjadi dalam perusahaan sebagai berikut:

Setelah peneliti berusaha menerapkan perencanaan penjadwalan mesin atau yg bisa kita sebut Preventive Maintenanceuntuk menekan angka kegagalan produk pada perusahaan atau untuk menurunkan angka persentase Failure Product terjadilah perubahan yang cukup signifikan pada angka Failure Product dibandingkan sebelum menerapkannya.

Untuk langkah pertama yang dilakukan oleh peneliti supaya mengetahui apa saja kendala-kendala yang terjadi pada perusahaan agar bisa mengklasifikasikan kalau-kalau ada penyebablain selain mesin yang mengakibatkan terjadinya Failure Product pada UMKM, peneliti menerapkan metode Fishbone untuk mencari sebab akibat apa saja 
kendala yang terjadi. Caranya sendiri ialah dengan memasukkan dimensi dari Preventive Maintenance kedalam kolom-kolom tulang ikannya Fishbone.

\section{SIMPULAN}

Penerapan Preventive Maintenance pada UMKM Pangan Sejahtera Pabrik Tauco Kota Sukabumi benar-benar bekerja sesuai tujuan yang penulis mau yaitu menekan angka Failure Product yang cukup tinggi. Dengan bantuan analisis dari metode Fishbone juga penulis menemukan permasalahan lain yang terjadi pada bagian produksi dank arena adanya analisis dari metode Fishbone tersebut penulis dapat membuatkan solusi untuk perusahaan. Preventive maintenance ini akan diterapkan secara permanen oleh pimpinan perusahaan.

\section{DAFTAR PUSTAKA}

Assauri, S. (2008). Manajemen Produksi dan Operasi, Jakarta: Fakultas Ekonomi Universitas Idnonesia

Ishikawa, K. (1992). Pengendalian Mutu Terpadu. Diterjemahkan oleh Budi Santoso. Bandung: Remaja Rosdakarya

Juliani, R.D. (2008). Sebab-sebab Kegagalan Produk Baru. Universitas Pandanaran Puspitasari, N. B., Martanto, A. (2014). Penggunaan FMEA dalam Mengidentifikasi Risiko Kegagalan Proses Produksi Sarung Atm (Alat Tenun Mesin) Studi Kasus PT Asaputex Jaya Tegal. Jurnal Teknik Industri, 9(2), 93-98

Sudrajat, D., Sumbodo. W., Suharmanto, A. (2016). Pengaruh Preventive Maintenance terhadap Hasil Produksi pada Proses Produksi Mesin Area Line D di PT. Triangle Motorindo. Skripsi: Universitas Negeri Semarang 